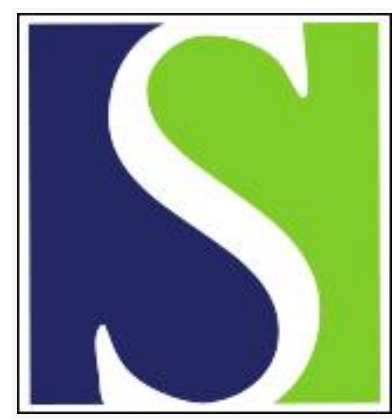

Scand J Work Environ Health 1994;20(3):223-226

https://doi.org/10.5271/sjweh.1404

Issue date: 01 Jun 1994

Re: "Role of the herbicide atrazine in the development of non-Hodgkin's lymphoma" by S Hoar Zahm, DD Weisburger, KP Kantor, FF Holmes, A Blair. Scand J Work Environ Health 1993; 19:108-14.

by Crosignani $P$, Berrino $F$

Affiliation: Epidemiology Unit, National Cancer Institute, I-20133 Milan, Italy.

Refers to the following text of the Journal: 1993;19(2):108-114

Key terms: agriculture; atrazine; cancer; case-referent study; epidemiology; herbicide; herbicide atrazine; letter to the editor; non-Hodgkin's lymphoma; occupation; triazine

This article in PubMed: www.ncbi.nlm.nih.gov/pubmed/7973496 


\section{Re: "Role of the herbicide atrazine in the development of non-Hodgkin's lymphoma" by S Hoar Zahm, DD Weisburger, KP Kantor, FF Holmes, A Blair. Scand J Work Environ Health 1993;19:108-14.}

The association between exposure to the herbicide atrazine and the risk of non-Hodgkin's lymphoma has been recently analyzed by Sheila Hoar Zahm and her colleagues (1) by considering four data sets from population-based case-referent studies conducted in the United States, namely, in Kansas (2), Nebraska (3), and Iowa-Minnesota (4). The author's final judgment was, ". . . these data provide little evidence that atrazine is associated with non-Hodgkin's lymphoma among white men [p 113]." The interpretation of the figures on which these conclusions are based is, however, problematic and requires further consideration.

All of the studies showed an increased risk associated with atrazine exposure, ranging from 1.2 to 2.7 , with reference to the unexposed subjects. In order to take into account potential confounding by the use of other herbicides and insecticides previously shown to be associated with the risk of non-Hodgkin's lymphoma, the analysis was restricted to farmers. In three studies, adjusting for exposure to 2,4dichlorophenoxyacetic acid $(2,4-D)$ and organophosphate insecticides (table 4 of reference 1) led only to minor changes of the risk associated with atrazine exposure. However, in the Nebraska study, risk showed a considerable decrease when exposures to 2,4-D and organophosphate insecticides were taken into account. Thus these two factors (2,4-D and organophosphate insecticides) appear as confounders of the association in the Nebraska data set.

The strength of confounding can be expressed by the confounding risk ratio [ie, the ratio between the unadjusted odds ratio (OR) for the exposure of interest $\mathrm{E}$ and the $\mathrm{OR}$ for the exposure to $\mathrm{E}$ adjusted for confounder C (5)]. Determinants of this entity are (i) the $\mathrm{OR}$ associated with exposure to $\mathrm{C}$ and (ii) the association between $\mathrm{E}$ and $\mathrm{C}$. A confounding rate ratio is always less than the odds ratio related to the confounder and approaches it only when the association between the exposure of interest and the confounder is very strong. The confounding risk ratios were evaluated for each study. Risk estimates for 2,4-D and organophosphate insecticides were derived from the original papers $(2,3,4)$. All of the figures were plausible, except those computed for the $\mathrm{Ne}$ braska study. The relevant figures are shown in table 1 . The risk associated with the exposure to 2,4-D was 1.5 and the confounding risk ratio for $2,4-\mathrm{D}$ was 1.5 . The same occurred for exposure to organophosphate insecticides, where an OR of 2.4 was associated with a confounding risk ratio of 2.4 . The identity between the confounding risk ratios and the OR values suggest that the association between atrazine and other exposure was very strong in the Nebraska data set. In these situations it is extremely difficult, or impossible, to distinguish between the effect of the two factors, and risk estimates for the effect of each factor are not reliable.

Another point of doubt arises when trends by duration of atrazine use and by average annual days of personal handling of atrazine are considered (table 5 of reference 1). If we compare the risk of the two extreme categories of duration relative to farmers without atrazine use, a twofold risk exists between

Table 1. Odds ratios (OR) associated with exposure to atrazine, 2,4-dichlorophenoxyacetic acid (2,4-D) and organophosphate insecticides; the confounding rate ratios for adjustment for 2,4-D and organophosphate insecticides of the OR associated with atrazine exposure - Nebraska study, farmers. ${ }^{a}$

\begin{tabular}{|c|c|c|c|c|c|c|}
\hline \multicolumn{3}{|c|}{ OR for exposure to atrazine } & \multicolumn{2}{|c|}{ Confounding rate ratios } & \multirow{2}{*}{$\begin{array}{c}\begin{array}{c}\text { OR for expo- } \\
\text { sure to } \\
2,4-D\end{array} \\
\begin{array}{c}\text { Adjusted } \\
\text { for age }\end{array}\end{array}$} & \multirow{2}{*}{$\begin{array}{c}\text { OR for } \\
\text { exposure to } \\
\text { organo- } \\
\text { phosphate } \\
\text { insecticides } \\
\begin{array}{c}\text { Adjusted } \\
\text { for age }\end{array}\end{array}$} \\
\hline $\begin{array}{l}\text { Adjusted } \\
\text { for age }\end{array}$ & $\begin{array}{l}\text { Adjusted for } \\
\text { age and } \\
2,4-D\end{array}$ & $\begin{array}{l}\text { Adjusted for } \\
\text { age and } \\
\text { organo- } \\
\text { phosphate } \\
\text { insecticides }\end{array}$ & 2,4-D & $\begin{array}{c}\text { Organo- } \\
\text { phosphate } \\
\text { insecticides }\end{array}$ & & \\
\hline 1.7 & 1.1 & 0.7 & 1.5 & 2.4 & 1.5 & 2.4 \\
\hline
\end{tabular}


them $(2.5 / 1.2=2.1)$ that remains after adjustment for 2,4-D $(1.9 / 0.8=2.4)$, after adjustment for organophosphate insecticides $(1.0 / 0.5=2.0)$, and after adjustment for both $(0.8 / 0.4=2.0)$. The same occurs for the "average annual days personally handled atrazine" for which a 2.4 risk between the two extreme categories $(3.1 / 1.3=2.4)$ remains after adjustment for $2,4-\mathrm{D}(2.4 / 0.9=2.7)$, for organophosphate insecticides $(1.3 / 0.7=1.9)$, and for both $(1.4 / 0.6=2.3)$. The apparent protection among the lowest categories of exposure to atrazine is difficult to explain, but the dose-response does not vanish when 2,4-D and organophosphate insecticides are adjusted for.

In table 5 of the report in question (1) latency is also considered. Data are presented separately for those with 20 or more years elapsed since the first use of atrazine. The risk was evident only among those for which the latency was shorter (ie, after 1965). It is, however, doubtful that these figures can be considered as an analysis of latency alone. Since 1965 , the amount of herbicides used per year in the United States has quadrupled (6), and the calendar year appears not only as a determinant of the latency, but also as a determinant of the frequency and intensity of exposure, both of which was much greater after 1965 than before. Thus the analysis of latency presented in the paper does not seem informative, as it does not take into account the intensity of exposure.

Another point reported against the role of atrazine exposure in the etiology of non-Hodgkin's lymphomas is that in the Iowa and Minnesota studies and in the combined analysis the risk among those who reported having personally handled atrazine was not higher than the risk of those who did not. These findings are not uncommon in epidemiologic studies on agricultural exposures. For instance, in the IowaMinnesota study (4), the risk associated with the use of phenoxyacetic acids was equal for those who personally handled the acids and those who did not (table 3 and table 6 of reference 4 ). The reasons for these apparent inconsistencies are not obvious. Nevertheless, it is worth noting that atrazine is not usually applied more than twice in a year. Atrazine is a very stable chemical (7), and it is possible that working in treated fields can be the most important and continuous instance of exposure, rather than the application of the herbicide. Last but not least, in the combined analysis, the confidence intervals of risk for those who directly handled atrazine and for those who did not show a considerable overlap.

The main issue, however, remains the reconsideration of the analysis of the Nebraska study data set, where, as outlined before, control of confounding leads to puzzling results. Even though the authors stated that "This large number of subjects and the detailed nature of the study questionnaires allowed us to examine the risks for specific agricultural exposures with sufficient power to adjust for other agricultural and nonagricultural exposures [p 113]," power to adjust for confounders also depends on the association between them and the exposure of interest. There can be instances in which associations between factors are so strong that adjustment is not possible. In these cases it would be prudent to consider the data set as inadequate to disentangle the effect of a single pesticide.

Atrazine is a member of a class of chemicals, the triazines, widely used as herbicides. In some European countries, due to the pollution of drinking water, atrazine has been banned, and often replaced by other triazines. There is also ongoing research to create triazine-resistant crops (eg, tobacco).

Atrazine has been reputed to be nongenotoxic (8), and a role in hormonally mediated tumors has been proposed (7). Nevertheless, atrazine is mutagenic in some experimental systems (7) and has been reputed to be genotoxic by the Italian Toxicological Commission (9). Animal experiments $(10,11)$ show a carcinogenic effect for lymphatic and hematopoietic tissue, for which a hormone-mediated mechanism is unlikely.

Other triazines, simazine and terbutylazine, are still widely used. These differ from atrazine only in their alchyl lateral groups. As one of the first biological transformations for triazine in mammals is the dealchylation of the triazinic ring (12), it is plausible that all of the aforementioned triazines also share biological hazards. Atrazine is the oldest and most widely used triazine, and probably the only one for which an epidemiologic assessment of the effect of exposure in humans is possible. As the study-pooled estimates were strongly influenced by the Nebraska study, and as the most-detailed analysis relied only on this particular study, it seems to us that a careful reconsideration of the analysis of this study would be of scientific and public health interest.

\section{References}

1. Hoar Zahm S, Weisburger DD, Kantor KP, Holmes FF, Blair A. Role of the herbicide atrazine in the development of non-Hodgkin's lymphoma. Scand J Work Environ Health 1993;19:108-14.

2. Hoar SK, Blair A, Holmes FF, Boysen CD Robel RJ, Hoover R, Fraumeni JF Jr. Agricultural herbicide use and risk of lymphoma and soft-tissue sarcoma. JAMA 1986;256:1141-47.

3. Hoar Zahm S, Weisburger DD, Babbitt PA, Saal RC, Vaught JB, Kantor KP, et al. A case-control study of non-Hodgkin's lymphoma and the herbicide 2,4dichlorophenoxyacetic acid (2,4-D) in eastern Nebraska. Epidemiology 1990;1:349-56.

4. Cantor KP, Blair A, Everett G, Gibson R, Burmeister LF, Brown LM, et al. Pesticide and other agricultural risk factors for non-Hodgkin's lymphoma among men in Iowa and Minnesota. Cancer Res 1992;52:244755.

5. Breslow NE, Day NE. Statistical methods in cancer research; vol 1 (The analysis of case-control studies). Lyon: International Agency for Research on Cancer (IARC), 1980. IARC scientific publications; no 32.

6. Zilberman D, Schmitz A, Casterline G, Lichtenberg $\mathrm{E}$, Siebert $\mathrm{E}$. The economics of pesticide use and regulation. Science 1991;253:518-22. 
7. International Agency for Research on Cancer (IARC). Occupational exposures in insecticide application and some pesticides. Lyon: IARC, 1991:41-66. IARC monographs on the evaluation of carcinogenic risk to humans; vol 53.

8. World Health Organization (WHO). Drinking-water quality: guidelines for selected herbicides. Copenhagen: WHO, 1987. Environmental health criteria; no 27.

9. Commissione Consultiva Tossicologica Nazionale. Valutazione di un primo elenco di pesticidi (erbicidi). Roma: Istituto Superiore di Sanitá, 1990. Rapporti ISTISAN 1990; 90/12.

10. Pinter A, Torok G, Borzsonyi M, Surjan A, Csik M, Kelecseni Z, et al. Long-term carcinogenicity bioassay of the herbicide atrazine in F344 rats. Neoplasma 1990;37:533-44.

11. Donna A, Betta PG, Robutti F, Bellingeri D. Carcinogenicity testing of atrazine: preliminary report on a 13-month study on male Swiss albino mice treated by intraperitoneal administration. Med Lav 1989;8: $119-21$.

12. Adams NH, Levi PE Hodgson E. In vitro studies of the metabolism of atrazione, simazine and terbutryn in several vertebrate species. J Agric Food Chem 1990; $38: 1411-7$

Paolo Crosignani, MD, Franco Berrino, MD

Epidemiology Unit

National Cancer Institute

1 , Via Venezian

I-20133 Milan

Italy 


\section{Authors' reply}

In our recent article on the herbicide atrazine (1), we combined and reanalyzed data from three case-referent studies covering four states in the United States and found a significant $40 \%$ excess risk of nonHodgkin's lymphoma, the odds ratios (OR) for the four states ranging from 1.2 to 2.7. After adjustment for use of organophosphate insecticides and the herbicide 2,4-dichlorophenoxyacetic acid (2,4-D), the atrazine association was reduced overall to a nonsignifcant OR of 1.2 and reduced in three of the four individual states (OR 0.7-1.9).

Drs Crosignani \& Berrino raise several important issues regarding the analyses of combined data sets, as was used in our study of atrazine. We agree that the ability to control for confounding is the major issue in evaluating these data. Drs Crosignani \& Berrino question whether it is possible to disentangle the effects of atrazine from other exposures. Before confounding can be controlled, there must be variation in the exposure patterns between subjects. For example, if organophosphates and atrazine were always used together, one could not disentangle their individual effects. In the combined data set we analyzed, every cell of the $2 \times 2 \times 2$ tables (atrazine $\times$ organophosphates $\times 2,4-D$ ) had subjects, and there was sufficient variation to adjust atrazine for these other exposures. To evaluate confounding risk ratios in the Nebraska study, Drs Crosignani \& Berrino made comparisons to the odds ratios (which were based on a reference group of nonfarmers) for 2,4-D and organophosphates from the original report (2). The appropriate odds ratios, which were not available to Drs Crosignani \& Berrino, would have been those based on farmers who were nonusers of each pesticide (OR 1.8 for 2,4-D, OR 2.6 for organophosphates). With these numbers, the confounding risk ratios for 2,4D (1.5) and organophosphates (2.4) are slightly lower than the odds ratio for each pesticide. We agree com- pletely that there was strong confounding in this data set. That recognition motivated our paper. We also agree that there may be residual confounding even after adjustment, but, surely, even incompletely adjusted odds ratios are more informative than unadjusted data.

Drs Crosignani \& Berrino suggest that there may be an atrazine effect because the top duration and frequency categories have larger relative risks than the lowest categories, even though the range includes the null value. The top frequency category, however, was based on one exposed case and one exposed referent. We believe that this odds ratio is too unreliable to be used as the primary basis for interpretation. The odds ratios for the other two lower exposure categories are very similar with little indication of a trend.

Drs Crosignani \& Berrino correctly point out that the latency analyses, which showed larger odds ratios in more recent time periods, do not consider intensity of exposure. Evaluating frequency in each of the two time periods, we found adjusted odds ratios of $0.5,0.3$, and 0.9 for $1-5,6-20$, and $\geq 21 \mathrm{~d}$ per year of atrazine use among farmers who first used atrazine prior to 1966. For the farmers who first used atrazine in 1966 or later, the adjusted odds ratios were 0.8 and 1.5 for $1-5$ and $6-20 \mathrm{~d}$ per year. (There were no cases or referents reporting use of $\geq 20 \mathrm{~d}$ per year in the later time period.) Thus there is little indication of a trend with intensity or positive latency effect.

Observing higher risks for farmers who personally handled a pesticide than for farmers who did not handle it but merely worked on farms where it was used can add to a causal interpretation for an association. Drs Crosignani \& Berrino question the value of this comparison. We believe these measures can be informative because they may identify farm- 
ers with a greater probability of exposure. The IowaMinnesota study report (3) does not contain information on farmers who worked on farms where 2,4-D was used, but did not handle it. In addition, 2,4-D did not appear to be much of a risk factor of non-Hodgkin's lymphoma in that study. The odds ratios for ever having handled 2,4-D and for having handled 2,4-D without protective equipment were both nonsignifcant 1.2. In the Kansas (4) and Nebraska (2) studies, where 2,4-D was significantly associated with non-Hodgkin's lymphoma, personal handling of 2,4-D and longer time spent in possibly contaminated workclothes increased the risk. For the current study, in our judgment, the lack of increased risk with handling atrazine weakened the causal interpretation.

In the United States, apparently as in Italy, atrazine is generally not applied many times per year. In the states of our study, atrazine is typically used during the planting of corn and soybeans. It should be noted, however, that in the Nebraska study $81 \%$ of the exposed cases and $87 \%$ of the exposed referents reported using atrazine more than $2 \mathrm{~d}$ a year. We doubt that there is much exposure from working in treated fields in our study because the crops grown (typically corn and soybeans) do not require much work in treated fields.

We share Drs Crosignani \& Berrino's concern over the possible health hazards of atrazine. In our study of 993 non-Hodgkin's lymphoma cases and 2918 referents with 130 cases and 249 referents exposed to atrazine, the small nonsignificant adjusted odds ratio suggests that use could not have been a strong risk factor for non-Hodgkin's lymphoma. Our study says nothing about the possible role of atrazine in other human health outcomes. Atrazine is genotoxic $(5,6)$, causes cancer in animals $(7-10)$, and has been linked to ovarian cancer in women (11). Given the hormonal activities of atrazine $(12,13)$, the highest priority should be given to replicating the ovarian cancer study and evaluating atrazine's relationship with cancers of the breast, endometrium, and prostate in populations exposed occupationally and populations exposed through contaminated drinking water. Other ongoing studies, such as the multicenter case-referent study of lymphoma in Italy and the prospective cohort Agricultural Health Study in the United States (14), should shed more light on these important issues.

\section{References}

1. Hoar Zahm S, Weisenburger DD, Cantor KP, Holmes FF, Blair A. Role of the herbicide atrazine in the development of non-Hodgkin's lymphoma. Scand J Work Environ Health 1993;19:108-14.

2. Zahm SH, Weisenburger DD, Babbitt PA, Saal RC, Vaught JB, Cantor KP, et al. A case-control study of non-Hodgkin's lymphoma and the herbicide 2,4dichlorophenoxyacetic acid (2,4-D) in eastern Nebraska. Epidemiology 1990;1:344-56.

3. Cantor KP, Blair A, Everett G, Gibson R, Burmeister
LF, Brown LM, et al. Pesticides and other agricultural risk factors for non-Hodgkin's lymphoma among men in Iowa and Minnesota. Cancer Res 1992;52: $2447-55$.

4. Hoar SK, Blair A, Holmes FF, Boysen CD, Robel RJ, Hoover R, et al. Agricultural herbicide use and risk of lymphoma and soft-tissue sarcoma. JAMA 1986; 256:1141-7.

5. Weisenburger DD, Joshi SS, Hickman TI, Babcook DM, Walker BA, Mirvish SS. N-Nitroso-atrazine (NNAT): synthesis, chemical properties, acute toxicity, and mutagenicity. In: American Association for Cancer Research. Proceedings of the American Association for Cancer Research; 1987 May 20-23; Atlanta (GA). Philadelphia, PA: American Association for Cancer Research, 1987:103.

6. Weisenburger DD, Joshi SS, Hickman TI, Walker BA, Lawson TA. Mutagenesis tests of atrazine and nitrosoatrazine: compounds of special interest to the Midwest. In: American Association for Cancer Research. Proceedings of the American Association for Cancer Research; 1988 May 25-28; New Orleans (LA). Philadelphia, PA: American Association for Cancer Research, 1988:421

7. Mayhew DA, Taylor GD, Smith SH, Banas DA. Twenty-four month combined chronic oral toxicity and oncogenicity study in rats utilizing atrazine technical: conducted by American Biogenics Corporation for Ciba-Geigy Corporation; study number $410-1102$. Washington, DC: United States Environmental Protection Agency, 1986; April 29, accession number $262714-262727$.

8. Pinter A, Torok G, Borzsonyi M, Surjan A, Csik M, Kelecseni $Z$, et al. Long-term carcinogenicity bioassay of the herbicide atrazine in F344 rats. Neoplasma 1990;37:533 - 44.

9. Donna A, Betta PG, Gagliardi F, Chiazza GF, Gallareto M, Gabutto V. Preliminary experimental contribution to the study of possible carcinogenic activity of two herbicides containing atrazine-simazine and trifluralin as active principles. Pathologica 1981;73:70721.

10. Donna A, Betta PG, Robutti F, Bellingeri D. Carcinogenicity testing of atrazine: preliminary report on a 13-month study on male Swiss Albino mice treated by intraperitoneal administration. Med Lav 1986;8: $119-21$.

11. Donna A, Crosignani P, Robutti F, Betta PG, Bocca $\mathrm{R}$, Mariani N, et al. Triazine herbicides and ovarian epithelial neoplasms. Scand J Work Environ Health 1989;15:47-53.

12. International Agency for Research on Cancer (IARC). Occupational exposures in insecticide application, and some pesticides. Lyon: IARC, 1991:41-66. IARC monographs on the evaluation of carcinogenic risks to humans; vol 53.

13. Morseth S. Fourteen-day repeated dose oral toxicity/ hormone study in female albino rats exposed to atrazine: laboratory project number 483-268: conducted by Hazelton Laboratories America, Inc. Washington, DC: United States Environmental Protection Agency, 1990; March 7, master record identification number 41510901 .

14. Alavanja MCR, Akland G, Baird D, Blair A, Bond A, Dosemeci $M$, et al. Cancer and non-cancer risk to women in agriculture and pest control: the Agricultural Health Study. J Occup Med. In press.

Shelia Hoar Zahm, ScD, Aaron Blair, PhD

National Cancer Institute

Executive Plaza North 418

Bethesda, Maryland 20892

USA 